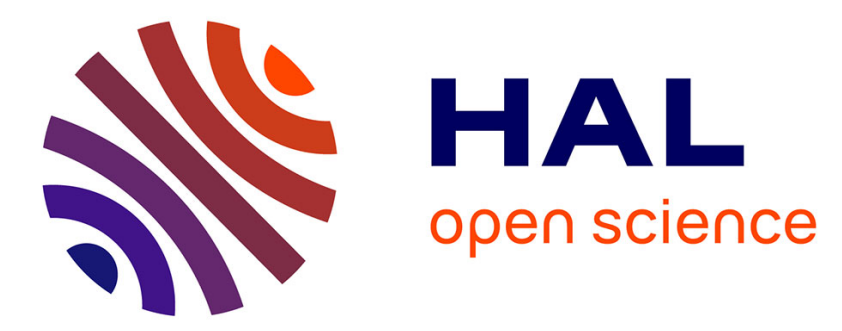

\title{
Risks and optimal migration duration: The role of higher order risk attitudes
}

\author{
Siwar Khelifa
}

\section{To cite this version:}

Siwar Khelifa. Risks and optimal migration duration: The role of higher order risk attitudes. 2020. halshs-02940346

\section{HAL Id: halshs-02940346 \\ https://shs.hal.science/halshs-02940346}

Preprint submitted on 16 Sep 2020

HAL is a multi-disciplinary open access archive for the deposit and dissemination of scientific research documents, whether they are published or not. The documents may come from teaching and research institutions in France or abroad, or from public or private research centers.
L'archive ouverte pluridisciplinaire HAL, est destinée au dépôt et à la diffusion de documents scientifiques de niveau recherche, publiés ou non, émanant des établissements d'enseignement et de recherche français ou étrangers, des laboratoires publics ou privés. 
UMR 5824

93. chemin des Mouilles 69130 Ecully - France

Maison de l'Universite, Bâtiment B 10, rue Trefilerie 42023 Saint-Etienne cedex $02 \cdot$ France

http://www.gate.cnrs.fr gate@gate.cnrs.fr

\title{
Risks and optimal migration duration: The role of higher order risk attitudes
}

\section{Siwar Khelifa}

\begin{abstract}
:
Using a bivariate expected utility framework, we develop a two-period model where households determine, in the presence of risks, the parents' migration duration when children are left behind. Our model suggests that the optimal migration duration may respond differently to an increase in a given risk. We provide conditions under which it is optimal for households to decrease the parents' migration duration despite an income risk in the place of origin, and to increase it even though the income in the place of destination is risky. The idea of preference for "harm disaggregation" is used to explain the results. In the absence of uncertainty, we also show the role of the interaction between child human capital and wealth in the household's utility function in determining the optimal migration duration of parents. Empirical implications of this analysis are presented in the last part of the paper.
\end{abstract}

\section{Keywords:}

Child human capital, Higher order risk attitudes, Labor migration, $N$ th degree Risk, Stochastic dominance

JEL codes:

D61, D81, J61 


\title{
Risks and optimal migration duration: The role of higher order risk attitudes
}

\author{
Siwar Khelifa*
}

September 2020

\begin{abstract}
Using a bivariate expected utility framework, we develop a two-period model where households determine, in the presence of risks, the parents' migration duration when children are left behind. Our model suggests that the optimal migration duration may respond differently to an increase in a given risk. We provide conditions under which it is optimal for households to decrease the parents' migration duration despite an income risk in the place of origin, and to increase it even though the income in the place of destination is risky. The idea of preference for "harm disaggregation" is used to explain the results. In the absence of uncertainty, we also show the role of the interaction between child human capital and wealth in the household's utility function in determining the optimal migration duration of parents. Empirical implications of this analysis are presented in the last part of the paper.
\end{abstract}

Keywords: Child human capital, Higher order risk attitudes, Labor migration, $N$ th degree Risk, Stochastic dominance

JEL Classification: D61, D81, J61

*Univ Lyon, Université Lumière Lyon 2, GATE UMR 5824, F-69130 Ecully, France E-mail address: khelifa@gate.cnrs.fr. ORCID id: 0000-0001-9211-4969. 


\section{Introduction}

Temporary labor mobility characterizes migration, both internationally and domestically, in many countries and regions worldwide (IOM, 2020). An estimated 4.9 million labor migrants entered OECD countries through temporary migration programs in 2017 (OECD, 2019). In the case of the Philippines, Cortes (2015) provides estimates of roughly $10 \%$ of the labor force working abroad temporarily and not being permitted to move overseas with their families. As a matter of fact, temporary labor migration also often results in separation of families, as illustrated by the growing number of children around the world being left behind in the care of the remaining family members or other caregivers, while one or both parents are away. In China alone, for example, an estimated 69 million children were left behind by one or both parents migrating to cities in 2015, accounting for about one third of all rural children in China ${ }^{1}$. This number was approximated to 1 million in Sri Lanka in 2005 (PintoJayawardena et al., 2006), and to about 1.5 to 3 million in the Philippines (Cortes, 2015). When associated with family separation, migration has been shown to have an adverse effect on the family left behind. Particularly, the negative consequences of parental migration on the school enrollment and the school performance, as well as on the health and psychological status of left-behind children can be deeply troubling, as reviewed by Antman (2013) and Fellmeth et al. (2018).

In this paper, we present a model that shows how optimal migration duration varies when family separation is accounted for and how it reacts to various types of risks that the migrantsending household may face. Previous theoretical literature has long associated uncertainty and risks to either migration decisions or other economic decisions in a migration context (Stark and Levhari, 1982; Katz and Stark, 1986; Galor and Stark, 1991). In the particular literature on return migration, Dustmann (1997) analyzes the optimal migration duration in a stochastic environment. He defines the optimal migration duration as the solution of a lifetime allocation problem between the country of origin and the host country, where incomes from each country depend on the time spent in the country and on a risky parameter.

In a vein similar to Dustmann (1997), we investigate the optimal migration duration in a risky context in a two period model, and we analyze how the household's preferences

\footnotetext{
${ }^{1}$ UNICEF 2018 China Office Annual Report, available at https://www.unicef.org/about/ annualreport/files/China_2018_COAR.pdf. Accessed on 04/06/2020
} 
affect the optimal migration duration depending on the risk levels considered. Our study distinguishes itself from and complements Dustmann's in at least three important ways.

First, contrary to the individual model of migration decision considered by Dustmann (1997), we focus on temporary migration when children are left behind. ${ }^{2}$ Therefore, the household's lifetime utility depends not only on a monetary variable (wealth level) but also on a non-monetary variable (the child human capital level). Moreover, since this type of migration implies a reduction in the time spent with children, we model migration as a time disinvestment in the child human capital, and the migration duration as the level of this disinvestment. Modeling the optimal migration duration as the solution of a resource transfer problem from the sub-period of migration to the sub-period of non-migration is close to a saving problem in a bivariate framework, where the two arguments of the utility function are a wealth level and a health level (see e.g., Liu and Menegatti, 2019a,b). Yet, our model differs from these models in the sense that the sacrifice is performed in a non-monetary dimension (the child human capital) in order to get future monetary benefits. This novelty creates new cross effects in our model that are worth investigating.

Second, we consider a wider set of risks. Dustmann (1997) introduces uncertainty by defining two risks on the country of origin and the host country incomes. He limits his analysis to Taylor approximations of order two, which is equivalent to considering weak risks. As a consequence, he only compares risk levels à la Rotschild-Stiglitz (Rothschild and Stiglitz, 1970). In this paper, we extend the analysis to different risk levels, and we investigate changes of order higher than two using the concept of $n$ th-order stochastic dominance (see e.g., Eeckhoudt and Schlesinger, 2006). Additional properties of risk perception of order higher than two have received growing attention in recent years, in various domains of economic analysis that investigate choices under risk. ${ }^{3}$ They have been shown to have determining effects on different economic behaviors of decision makers, when exposed to changes in the levels of the risk considered. Important applications include, among others, saving decisions (Eeckhoudt and Schlesinger, 2008), rent seeking activities (Treich, 2010), environmental policies (Baiardi and Menegatti, 2011) and health decisions (Courbage and Rey, 2016). Various experimental

\footnotetext{
${ }^{2}$ Note that Dustmann (2003) investigates the role of children in the return migration decision-making when all the household members are migrants, but does not consider the case when labor migration implies family separation.

${ }^{3}$ Examples include prudence and temperance as risk perceptions of order 3 and 4, respectively (Kimball et al., 1990; Kimball, 1992). See Eeckhoudt and Schlesinger (2013) for a review of the theoretical work on higher-order risk attitudes.
} 
and empirical works have also been conducted, showing the prevalence and the importance of higher order risk attitudes (see Trautmann and van de Kuilen (2018) for a review). Furthermore, in addition to the risk on the return on migration and on the household income risk, our model introduces a non-monetary risk on the child human capital.

Finally, Dustmann (1997) considers the case where risks are not independent. In this paper, our goal is to focus on the effect of each risk to analyze how the two (monetary and non-monetary) dimensions of the household's lifetime utility interact with each other. That is why we consider each risk separately.

We initially derive a number of comparative statics for the optimal duration of migration, in a context with no risks. We find that the optimal migration duration reacts heterogeneously to increases in the household income during the migration of the parent and to increases in the future child human capital status when the migrant parent is back. We show that this heterogeneity depends on the sign of the child human capital state dependence, i.e. the variation in the marginal utility of income with respect to the child human capital status. ${ }^{4}$

With the introduction of risks, we show that households do reoptimize in the face of risk, and that the optimal migration duration varies as a result. First, we find that the effects of various risks on the migration duration depend on the type and the timing of the risk considered, as they differently influence either the marginal cost of the migration duration or its marginal benefit. Second, as in Dustmann (1997), we find that prudence, defined as the decision of building up precautionary savings in order to better face future income risks (Kimball et al., 1990), plays a fundamental role when we consider comparisons of risk levels à la Rotschild-Stiglitz. ${ }^{5}$ However, since we do not limit our analysis to weak risks, we are also able to show that conditions of higher order, such as temperance and edginess ${ }^{6}$, and other higher order risk aversion attitudes play a decisive role in the direction of changes in the optimal migration duration with respect to changes in the level of a given risk.

Moreover, the use of a bivariate lifetime utility function depending on the income and

\footnotetext{
${ }^{4}$ We keep our analysis general as we make no restrictive assumption on the sign of the child human capital state dependence. The three cases are possible, the marginal utility of income may increase, decrease or remain constant with an increase in the child human capital status (see section 2 for details).

${ }^{5}$ Note that Dustmann (1997) does not employ the term "prudence". Yet, he shows the importance of the derivative of order three, which defines prudence.

${ }^{6} \mathrm{An}$ agent is temperant when an unavoidable (background) risk leads him to reduce exposure to another risk even if the two risks are statistically independent (Kimball, 1992). Edginess, first introduced by LajeriChaherli (2004), captures the reactivity to multiple risks on precautionary motives. It is a necessary condition for preferences to exhibit standard prudence or precautionary vulnerability.
} 
the child human capital for the household, allows for cross-derivatives of the utility function to affect the optimal migration duration. Particularly, we show that cross-prudence in child human capital is relevant in determining changes in the migration duration when the household faces an income risk during the migration of the parent. Similarly, we show that cross-prudence in wealth is also relevant in determining changes in the migration duration when the child human capital becomes at risk. Finally, our analysis shows the existence of incentives of opposite direction for households to adjust the migration duration whenever the migrant's income becomes risky at destination. The net effect is governed by the relative strength of the motive to increase migration duration because of prudence and that of the motive to decrease it because of risk aversion. The optimal migration duration increases only if risk aversion is enough "weaker" for households than prudence.

The remainder of the paper is organized as follows. In section 2, we introduce the basic model with no risks. Section 3 investigates the effect of the introduction of risks on the optimal migration duration, considering three types of risks. Section 4 generalizes results to the case of an increase in risks in terms of $n$ th-order stochastic dominance. Section 5 addresses the case of risky return on the migration duration. Section 6 concludes.

\section{The Basic Model}

\section{$2.1 \quad$ Setup}

Consider a household with two parents and one child ${ }^{7}$. We assume that parents jointly make all economic decisions and that the child does not participate in the decision-making process. The household cares about her income but also about her child's human capital. Consider a two-period general framework. Preferences of the decision maker are represented by Von-Neumann-Morgenstern bivariate utility functions: $U(y, Z)$ in period 1 and $V(y, Z)$ in period 2, where $y$ denotes the household's income and $Z$ is the child's human capital. Child human capital is a multidimensional variable, with health and education being the most important forms of human capital (Currie, 2020). Parental time may affect different child outcomes differently, which raises the problem of how to aggregate these different effects in

\footnotetext{
${ }^{7}$ The model can be extended to the case of a household with more family members without affecting the results.
} 
order to get the overall impact. For simplicity, in our model, instead of considering the effect on each child outcome and aggregating the results, we follow the theoretical literature on child human capital investment and intergenerational mobility in using a summary metric of the child human capital status (see e.g., Becker et al., 2018).

We make standard assumptions on preferences ${ }^{8}$. First, $G$ (with $G=U, V$ ) is strictly increasing, i.e. the marginal utilities with respect to each argument are strictly positive $\left(G^{(1,0)}(y, Z)>0\right.$ and $\left.G^{(0,1)}(y, Z)>0, \forall(y, Z)\right)$. Second, $G$ is strictly concave, i.e. the decision maker is risk averse towards a single risk on each argument $\left(G^{(2,0)}(y, Z)<0\right.$ and $\left.G^{(0,2)}(y, Z)<0, \forall(y, Z)\right)$.

We do not introduce any assumption on the cross second derivatives of $G\left(G^{(1,1)}\right)$ and thus consider the three possible cases: $G^{(1,1)}=0, G^{(1,1)}<0$ and $G^{(1,1)}>0$. The sign of $G^{(1,1)}$ describes how the marginal utility of income changes when the level of child human capital increases. Consequently, it also determines which functional form can be used for the utility functions $U$ and $V$. In particular, $G^{(1,1)}=0$ means that the child's human capital level does not modify the income marginal utility. In this case, the additive separability between the household's earnings and the child's human capital should be assumed $\left(G(y, Z)=u_{1 G}(y)+\right.$ $u_{2 G}(Z)$ with $u_{1 G}^{\prime}>0, u_{1 G}^{\prime \prime}<0, u_{2 G}^{\prime}>0$ and $\left.u_{2 G}^{\prime \prime}<0\right)$. If $G^{(1,1)}<0$, we are assuming the non-separable form of the utility function $\left(G(y, Z)=u_{G}\left(y+f_{G}(Z)\right)\right.$ with $u_{G}^{\prime}>0, u_{G}^{\prime \prime}<0$, $f_{G}^{\prime}>0$ and $f_{G}^{\prime \prime}<0$, where $f_{G}(Z)$ is the monetary equivalent of the child's human capital level $Z$ ). The negative sign of the cross-derivative means that the marginal utility of income is lower when the child has higher levels of human capital. Finally, if $G^{(1,1)}>0$, the utility of an additional unit of income is higher when the child has higher levels of human capital. We can thus consider the multiplicative separability between the household's earnings and the child's human capital $\left(G(y, Z)=u_{1 G}(y) u_{2 G}(Z)\right.$ with $u_{1 G}^{\prime}>0, u_{1 G}^{\prime \prime}<0, u_{2 G}^{\prime}>0$ and $\left.u_{2 G}^{\prime \prime}<0\right)^{9}$.

In the theoretical literature about child human capital investment and intergenerational mobility, many papers assume the additive separability of the parental utility function (see e.g., Kasy et al., 2012; Myerson, 2017; Becker et al., 2018), while some do not impose any

\footnotetext{
${ }^{8}$ The partial and the cross-derivatives $f^{\left(k_{1}, k_{2}\right)}$ of a function $f$ with two arguments $x_{1}$ and $x_{2}$ are given by the following expression: $\frac{\partial^{k_{1}+k_{2}} f\left(x_{1}, x_{2}\right)}{\partial x_{1}^{k_{1}} \partial x_{2}^{k_{2}}}, \forall k_{1}=0, \ldots, N, \forall k_{2}=0, \ldots, N$.

${ }^{9}$ Note that, mathematically, there may exist other functional forms for the utility function $G$ that lead to one of the three possible signs of the cross-derivative. However, we only consider the three cases that are the most used in economics.
} 
assumption on the functional form of the parental utility function (see e.g., Loury, 1981; Behrman, 1997). It is therefore difficult to determine which of these assumptions is a priori more conclusive, especially since no empirical evidence in favor of one or the other specification has been provided. Finally, we assume that $U$ and $V$ are $n$ times continuously differentiable.

\subsection{Analysis}

As specified in the introduction, the household makes a time disinvestment in child human capital when deciding to send a parent for migration ${ }^{10}$, with the aim of increasing the future wealth level ${ }^{11}$. In the first period, the parent migrates to the city, and the utility is that of the household left behind without the migrant (utility function $U$ ). The time disinvestment in child human capital following the parent's migration implies a decrease in the child's human capital that we denote as $m$. We assume that $m$ is an increasing function of the migration duration, denoted by $d$, such that $m=f(d)$, where $f^{\prime}(d)>0$. For simplicity and without loss of generality, we assume that $f(d)=d$, hence the following relationship: $m=d$. When the migrant returns home in the second period, the utility becomes that of the full household including the migrant (utility function $V$ ). The household chooses the migration duration that maximizes her lifetime utility. The maximization program writes as follows:

$$
\operatorname{Max}_{m} W(m)=U\left(y_{1}, Z_{1}-m\right)+\beta V\left(y_{2}+g(m), Z_{2}\right)
$$

where $\beta$ is the discount factor for the future utility, and $g(m)$ is the amount of money that the migrant parent brings back after returning home. In other words, $g(m)$ represents the return on the migration duration expressed in monetary units. We assume that $g^{\prime}(m)>0$ and $g^{\prime \prime}(m) \leq 0$ for all levels of $m$, i.e. that an increase in $m$ increases the monetary benefit in the second period but at a decreasing rate. We denote by $m^{*}$ the solution of the maximisation

\footnotetext{
${ }^{10}$ The loss of parental time and family disruption means less attention, supervision and care, less study and leisure hours and more engagement in the household activities for the children left behind, inducing an adverse effect on the different child outcomes (see e.g., McKenzie and Rapoport (2006) and Antman (2011) for education outcomes). This negative effect may even override any benefits from remittances, as shown by a series of recent studies on the academic performance and school attendance of these children, on their health (e.g., Nguyen, 2016) and on their socio-psychological behavior (e.g., Mazzucato et al., 2015).

${ }^{11}$ Previous research has emphasized that migration is a decision through which income can be increased (Harris and Todaro, 1970).
} 
problem (1). This solution is unique and fully characterized by the first order condition (FOC) of the maximisation program, $W^{\prime}\left(m^{*}\right)=0$, that writes as ${ }^{12}$ :

$$
-U^{(0,1)}\left(y_{1}, Z_{1}-m^{*}\right)+\beta g^{\prime}\left(m^{*}\right) V^{(1,0)}\left(y_{2}+g\left(m^{*}\right), Z_{2}\right)=0
$$

The first term of Eq. (2), $U^{(0,1)}\left(y_{1}, Z_{1}-m^{*}\right)$, represents the marginal cost of the migration duration, i.e. the loss of first-period utility due to the absence of the parent, while the second term, $g^{\prime}\left(m^{*}\right) V^{(1,0)}\left(y_{2}+g\left(m^{*}\right), Z_{2}\right)$, represents the marginal benefit of the migration duration, i.e. the expected gain of second period utility due to increases in the household income.

We establish some of the comparative statics properties of the optimal migration duration, $m^{*}$, that maximizes the inter-temporal utility of the household. The main results are summarized in the following proposition:

\section{Proposition 1.}

The optimal migration duration $\left(m^{*}\right)$ is:

(i) decreasing in the second-period income and increasing in the first period's child human capital,

(ii) increasing (respectively independent, decreasing) in the first-period income if $U^{(1,1)}<0$ (respectively $U^{(1,1)}=0, U^{(1,1)}>0$ ),

(iii) decreasing (respectively independent, increasing) in the second period's child human capital if $V^{(1,1)}<0$ (respectively $V^{(1,1)}=0, V^{(1,1)}>0$ ).

Proof See the Appendix.

The mechanisms behind the first comparative statics are very intuitive. First, when the second-period income increases, earnings from migration have a lower relative weight on the total household income, implying that parents would be willing to decrease the migration duration. Second, when the level of the child's human capital increases in the first period, it makes it less costly for the household to sacrifice her child's human capital, because the relative weight of this sacrifice has become smaller, and therefore increasing the migration

\footnotetext{
${ }^{12}$ Note that the second order condition (SOC), which writes as $W^{\prime \prime}(m)=U^{(0,2)}\left(y_{1}, Z_{1}-m\right)+$ $\beta\left(g^{\prime}(m)\right)^{2} V^{(2,0)}\left(y_{2}+g(m), Z_{2}\right)+\beta g^{\prime \prime}(m) V^{(1,0)}\left(y_{2}+g(m), Z_{2}\right)$, is always negative $\left(W^{\prime \prime}(m)<0 \forall m\right)$ with the assumptions made on $U, V$ and $g(m)$. As a result, the SOC for a maximum holds and $m^{*}$ is unique.
} 
duration.

Variations in the optimal migration duration $\left(m^{*}\right)$ are also affected by the first-period income and the second-period child human capital. However, the direction of these effects depend on the signs of $U^{(1,1)}$ and $V^{(1,1)}$, respectively. If $U^{(1,1)}<0$, it means that when the first period income increases, the marginal utility of the child human capital decreases, which makes it less costly for the household to sacrifice the child's human capital, increasing the migration duration $m^{*}$. However, if $U^{(1,1)}>0$, an increase in the first period household income increases the marginal utility of the child human capital, which makes it more difficult to sacrifice the child's human capital, thus decreasing the migration duration $m^{*}$. This hypothesis is consistent with previous studies of intergenerational mobility that emphasized that parents with higher incomes invest more, on average, on their children's human capital (see e.g. Heckman and Mosso, 2014; Becker et al., 2018). Finally, when $U^{(1,1)}=0$, the first period income has no effect on the optimal migration duration. The last comparative static can be explained as follows. When the second period's child human capital increases, it decreases the marginal benefit of migration, decreasing $m^{*}$, if $V^{(1,1)}<0$. However, if $V^{(1,1)}>0$, an increase in the second period's child human capital increases the marginal benefit from migration, thus increasing $m^{*}$. Finally, when $V^{(1,1)}=0$, the second period's child human capital has no effect on the optimal migration duration.

We deduce the following implications on the welfare of left-behind children. In the case of a parent's migration, and following an increase in the household income during the migration of the parent, a child is better off if the household has a marginal utility of income that increases with the child human capital status (i.e., the child human capital state dependence is positive). Similarly, following an increase in the child human capital when the parent is back, a child is better off if the household has a marginal utility of income that decreases when the child human capital increases (i.e., the child human capital state dependence is negative).

\section{Introduction of risks}

When making the decision to send a parent for migration, the household may consider some risks that she may face either in the near future (the first period) or in a distant future 
(the second period).

One important source of risk for rural households is agricultural income risk, especially related to particular episodes of weather failures (Paxson, 1992; Rose, 2001; Giles and Yoo, 2007; Bazzi, 2017). Similarly, non-agricultural households working in the informal economy are also exposed to income risk ${ }^{13}$. These workers are, most of the time, only offered shortterm jobs with absence of employment contracts, do not have access to social security or other employment benefits such as paid sick leave, and are usually not protected by labor laws and regulations (International Labour Office, 2018). These conditions make the income of these households risky.

The household's children can also be faced with an exogenous risk on their human capital. This risk can be related to different factors, with air pollution being one example. $93 \%$ of children worldwide were exposed to levels of air pollution above the World Health Organization guidelines in 2016 (World Health Organization, 2018). This air pollution may affect the child human capital through its effect on child health, schooling and cognitive functioning (see the review in Currie et al. (2014)). In our model, we particularly focus on pollutants that induce harm following a prolonged exposure (over weeks or even years), and therefore, we introduce a risk on child human capital only in the second-period.

In presence of risks, the household's expected utility has the following general expression:

$$
E\left[U\left(y_{1}+\tilde{\epsilon}_{1 w}, Z_{1}-m\right)\right]+\beta E\left[V\left(y_{2}+\tilde{\epsilon}_{2 w}+g(m), Z_{2}+\tilde{\epsilon}_{2 z}\right)\right],
$$

where $E$ denotes the expectation operator over the random variables $\tilde{\epsilon}_{k}(k=1 w, 2 w, 2 z)$ assumed actuarially neutral and mutually independent $\left(E\left(\tilde{\epsilon}_{k}\right)=0, \forall k\right)$. Next sections study the different cases of risks presented above.

\subsection{Income risk}

We first investigate the effect of the introduction of an income risk in the first period on the optimal migration duration, i.e. the case where $\tilde{\epsilon}_{2 w}=\tilde{\epsilon}_{2 z}=0$ in Eq. (3). In this case,

\footnotetext{
${ }^{13}$ The non-agricultural informal employment in all of the informal sector, the formal sector and in households reached, as a share of the total employment, $71.9 \%$ in Africa, $63.9 \%$ in the Arab States, $59.2 \%$ in Asia and the Pacific, 36.1\% in the Americas and 20.8\% in Europe and Central Asia in 2016 (International Labour Office, 2018).
} 
the household's expected utility becomes

$$
W_{\tilde{\epsilon}_{1 w}}(m)=E\left[U\left(y_{1}+\tilde{\epsilon}_{1 w}, Z_{1}-m\right)\right]+\beta V\left(y_{2}+g(m), Z_{2}\right) .
$$

The optimal migration duration, $m_{\tilde{\epsilon}_{1 w}}^{*}$, is given by the FOC $W_{\tilde{\epsilon}_{1 w}}^{\prime}\left(m_{\tilde{\epsilon}_{1 w}}^{*}\right)=0$ that writes as ${ }^{14}$

$$
-E\left[U^{(0,1)}\left(y_{1}+\tilde{\epsilon}_{1 w}, Z_{1}-m_{\tilde{\epsilon}_{1 w}}^{*}\right)\right]+\beta g^{\prime}\left(m_{\tilde{\epsilon}_{1 w}}^{*}\right) V^{(1,0)}\left(y_{2}+g\left(m_{\tilde{\epsilon}_{1}}^{*}\right), Z_{2}\right)=0 .
$$

Evaluating $W_{\tilde{\epsilon}_{1 w}}^{\prime}$ at $m^{*}$ in order to compare the two optimal values $m_{\tilde{\epsilon}_{1 w}}^{*}$ and $m^{*}$, we have

$$
W_{\tilde{\epsilon}_{1 w}}^{\prime}\left(m^{*}\right)=-E\left[U^{(0,1)}\left(y_{1}+\tilde{\epsilon}_{1 w}, Z_{1}-m^{*}\right)\right]+\beta g^{\prime}\left(m^{*}\right) V^{(1,0)}\left(y_{2}+g\left(m^{*}\right), Z_{2}\right),
$$

that is equivalent to (using Eq. (2))

$$
\left.W_{\tilde{\epsilon}_{1 w}}^{\prime}\left(m^{*}\right)=-E\left[U^{(0,1)}\left(y_{1}+\tilde{\epsilon}_{1 w}, Z_{1}-m^{*}\right)\right]+U^{(0,1)}\left(y_{1}+\tilde{\epsilon}_{1 w}, Z_{1}-m^{*}\right)\right) .
$$

This equation is negative (positive), resulting in $m_{\tilde{\epsilon}_{1 w}}^{*} \leq(\geq) m^{*}$, if $U^{(2,1)}(y, Z) \geq(\leq) 0$, $\forall(y, Z)$, i.e. whenever the household is cross-prudent (cross-imprudent) in the first period child human capital, following the terminology of Eeckhoudt et al. (2007). If this result is rather surprising at first glance, it can be easily explained. In the case where $U^{(2,1)}(y, Z) \geq 0$, the introduction of the monetary risk in the first period increases the marginal cost of the migration duration, compared with the situation without risk, since $E\left[U^{(0,1)}\left(y_{1}+\tilde{\epsilon_{1}}, Z-\right.\right.$ $\left.\left.m^{*}\right)\right] \geq U^{(0,1)}\left(y_{1}, Z-m^{*}\right)$ if $U^{(2,1)}(y, Z)$, while it leaves its marginal benefit unchanged. The prudent household thus decreases the optimal migration duration as it increases the expected marginal cost without modifying the marginal benefit. In terms of preference for the disaggregation of harms, using the terminology of Eeckhoudt and Schlesinger (2006), compared to a situation without risk, the household would prefer to sacrifice a lower level of child human capital in the period where she faces a harm, and therefore decreases the migration duration.

However, when the income risk is introduced in the second period, the situation corresponds to the case where $\tilde{\epsilon}_{1 w}=\tilde{\epsilon}_{2 z}=0$ in Eq. (3). The household's expected utility

\footnotetext{
${ }^{14}$ The SOC is verified by our assumptions.
} 
becomes

$$
W_{\tilde{\epsilon}_{2 w}}(m)=U\left(y_{1}, Z_{1}-m\right)+\beta E\left[V\left(y_{2}+\tilde{\epsilon}_{2 w}+g(m), Z_{2}\right)\right] .
$$

The optimal migration duration, $m_{\tilde{\epsilon}_{2 w}}^{*}$, is given by the FOC $W_{\tilde{\epsilon}_{2 w}}^{\prime}\left(m_{\tilde{\epsilon}_{2 w}}^{*}\right)=0$ that writes as

$$
-U^{(0,1)}\left(y_{1}, Z_{1}-m_{\tilde{\epsilon}_{2 w}}^{*}\right)+\beta g^{\prime}\left(m_{\tilde{\epsilon}_{2 w}}^{*}\right) E\left[V^{(1,0)}\left(y_{2}+\tilde{\epsilon}_{2 w}+g\left(m_{\tilde{\epsilon}_{2 w}}^{*}\right), Z_{2}\right)\right]=0 .
$$

Evaluating $W_{\tilde{\epsilon}_{2 w}}^{\prime}$ at $m^{*}$, we obtain

$$
W_{\tilde{\epsilon}_{2 w}}^{\prime}\left(m^{*}\right)=-U^{(0,1)}\left(y_{1}, Z_{1}-m^{*}\right)+\beta g^{\prime}\left(m^{*}\right) E\left[V^{(1,0)}\left(y_{2}+\tilde{\epsilon}_{2 w}+g\left(m^{*}\right), Z_{2}\right)\right],
$$

that is equivalent to (using Eq. (2))

$$
W_{\tilde{\epsilon}_{2 w}}^{\prime}\left(m^{*}\right)=-\beta g^{\prime}\left(m^{*}\right) V^{(1,0)}\left(y_{2}+g\left(m^{*}\right), Z_{2}\right)+\beta g^{\prime}\left(m^{*}\right) E\left[V^{(1,0)}\left(y_{2}+\tilde{\epsilon}_{2 w}+g\left(m^{*}\right), Z_{2}\right)\right] .
$$

This equation is negative (positive), resulting in $m_{\tilde{\epsilon}_{2 w}}^{*} \leq(\geq) m^{*}$, if $V^{(3,0)}(y, Z) \leq(\geq) 0$, $\forall(y, Z)$, i.e. if the household is imprudent (prudent) in wealth in the second period. Contrary to the previous case, in the case where $V^{(3,0)}(y, Z) \geq 0$, the introduction of the monetary risk in the second period increases the marginal benefit of the migration duration, compared with the situation without risk since $E\left[V^{(1,0)}\left(y_{2}+\tilde{\epsilon}_{2 w}+g\left(m^{*}\right), Z_{2}\right)\right] \geq V^{(1,0)}\left(y_{2}+g\left(m^{*}\right), Z_{2}\right)$, while it has no effect on the marginal cost. The prudent household thus increases her optimal migration duration as it increases the expected marginal benefit without modifying its marginal cost. In terms of preference for the disaggregation of harms, the household would prefer to increase the migration duration in order to get a higher wealth in the period where she faces the harm.

We summarize these results in the following proposition:

\section{Proposition 2}

The introduction of an income risk in the first period reduces (increases) the optimal migration duration, $m_{\epsilon_{1 w}^{*}}^{*} \leq(\geq) m^{*}$, if the household is cross-prudent (cross-imprudent) in child human capital in the first period.

The introduction of an income risk in the second period increases (reduces) the optimal migration duration, $m_{\tilde{\epsilon}_{2 w}}^{*} \geq(\leq) m^{*}$, if the household is prudent (imprudent) in wealth in the 
second period.

Proposition 2 shows that, for a household, the effect of an income risk on the optimal migration duration differs depending on the period in which the risk is introduced. It also suggests the following implications for the left-behind children. During the migration of a parent and if the household is cross-prudent in child human capital, a child is better off when the household is faced with a first-period income risk than with no risk, and that if the household is faced with a first-period income risk, the child is better off if the household is cross-prudent than if she is cross-imprudent in child human capital. However, the situation changes if the income risk is faced when the migrant parent is back. If the household is prudent in wealth in the second period, a child is better off when the household bears no risk than if she is faced with a second-period income risk, and that if the household is faced with a second-period income risk, the child is better off if the household is imprudent than if she is prudent in wealth.

$U^{(2,1)}(y, Z) \geq 0$ is consistent with the findings of De La Rupelle et al. (2009) who empirically showed that facing a risk of land expropriation (which is a first-period income risk) reduces the duration of migration in China. However, the New Economics of Labor Migration theory suggests that migration is used as a coping strategy to hedge against risk (Stark and Bloom, 1985; Stark, 1991), and therefore, the migration duration is expected to increase when the household income is risky in the first period, this hypothesis is consistent with $U^{(2,1)}(y, Z) \leq 0$. $V^{(3,0)}(y, Z) \geq 0$ is consistent with the theoretical proposition of Dustmann (1997) that the migration duration increases when the second-period income at home is riskier than that of the first period and the wage differential between destination and the place of origin is large.

\subsection{Child human capital risk}

Finally, we analyze the effect of the introduction of a child human capital risk in the second period on the migration duration, i.e. in the case where $\tilde{\epsilon}_{1 w}=\tilde{\epsilon}_{2 w}=0$ in Eq. (3). The household's expected utility becomes

$$
W_{\tilde{\epsilon}_{2 z}}(m)=U\left(y_{1}, Z_{1}-m\right)+\beta E\left[V\left(y_{2}+g(m), Z_{2}+\tilde{\epsilon}_{2 z}\right)\right]
$$


The optimal migration duration, $m_{\tilde{\epsilon}_{2 z}}^{*}$, is given by the FOC $W_{\tilde{\epsilon}_{2 z}}^{\prime}\left(m_{\tilde{\epsilon}_{2 z}}^{*}\right)=0$ that writes as

$$
-U^{(0,1)}\left(y_{1}, Z_{1}-m_{\tilde{\epsilon}_{2 z}}^{*}\right)+\beta g^{\prime}\left(m_{\tilde{\epsilon}_{2 z}}^{*}\right) E\left[V^{(1,0)}\left(y_{2}+g\left(m_{\tilde{\epsilon}_{2 z}}^{*}\right), Z_{2}+\tilde{\epsilon}_{2 z}\right)\right]=0 .
$$

Applying the same reasoning as before, we can easily show that $m_{\tilde{\epsilon}_{2 z}}^{*} \leq(\geq) m^{*}$, if $V^{(1,2)}(y, Z) \leq$ $(\geq) 0, \forall(y, Z)$, i.e. whenever the household is cross-imprudent (cross-prudent) in wealth in the second period. For example, if $V^{(1,2)}(y, Z) \geq 0$, the introduction of the child human capital risk in the second period increases the marginal benefit of the migration duration, compared with the situation without risk since $E\left[V^{(1,0)}\left(y_{2}+g\left(m^{*}\right), Z_{2}+\tilde{\epsilon}_{2 z}\right)\right] \geq V^{(1,0)}\left(y_{2}+g\left(m^{*}\right), Z_{2}\right)$, while it has no effect on the marginal cost. Therefore, the cross-prudent household in wealth increases her optimal migration duration as it increases the expected marginal benefit without modifying its marginal benefit. In terms of preference for the disaggregation of harms, the household would prefer to face the child human capital risk when it is coupled with a higher wealth, and therefore increases the migration duration. we obtain the following result:

\section{Proposition 3}

The introduction of a child human capital risk in the second period increases (reduces) the optimal migration duration, $m_{\tilde{\epsilon}_{2 z}}^{*} \geq(\leq) m^{*}$, if the household is cross-prudent (crossimprudent) in wealth in the second period.

Proposition 3 reveals that, if the household is cross-prudent in wealth in the second period, a left-behind child is better off when the household bears no risk than if she is faced with a second-period child human capital risk, and that if the household is faced with a second-period child human capital risk, the left-behind child is better off if the household is cross-imprudent than if she is cross-prudent in wealth.

\section{Increase in risks}

In Section 3, we investigated the effect of introducing a risk (an income risk and a child human capital risk) on the optimal migration duration. A subsequent and connected question is to examine how an increase in these risks modifies the optimal migration duration.

Consider two random (income or child human capital) variables $\tilde{\theta}_{k}$ and $\tilde{\epsilon}_{k}$ (with $k=1 w, 2 w$ 
or $2 z$ ) valued in some interval $[a, b]$ of the real line, with respective distribution functions $F$ and $G$. Starting from $F_{1}=F$ and $G_{1}=G$, define iteratively for $z \in[a, b]$

$$
F_{s+1}(z)=\int_{a}^{z} F_{s}(t) d t \text { and } G_{s+1}(z)=\int_{a}^{z} G_{s}(t) d t
$$

for $s=1,2, \ldots$. Then, $\tilde{\theta}_{k}$ is said to be riskier than $\tilde{\epsilon}_{k}$ (or, $\tilde{\theta}_{k}$ is said to be dominated by $\left.\tilde{\epsilon}_{k}\right)$ via $n$ th-order stochastic dominance if $G_{n}(z) \leq F_{n}(z)$ for all $z$, and if $G_{s}(b) \leq F_{s}(b)$ for $s=1,2, \ldots, n-1$. This is denoted as $\tilde{\theta}_{k} \preceq_{S D_{n}} \tilde{\epsilon}_{k}$.

From Ingersoll (1987), we know that $\tilde{\theta}_{k} \preceq_{S D_{n}} \tilde{\epsilon}_{k}$ is equivalent to $E\left[f\left(\tilde{\theta}_{k}\right)\right] \leq E\left[f\left(\tilde{\epsilon}_{k}\right)\right]$ for all functions $f$ with derivatives $f^{(1)}, f^{(2)}, \ldots, f^{(n)}$ such that $(-1)^{s+1} f^{(s)} \geq 0$ for $s=1,2, \ldots, n$. Hence, $\preceq_{S D_{n}}$ represents the common preferences of all the decision makers whose preferences satisfy risk apportionment of degrees 1 to $n$ in the terminology of Eeckhoudt and Schlesinger (2006). These decision makers prefer to disaggregate risk across equiprobable states of nature. When the first $n-1$ moments of $\tilde{\theta}_{k}$ and $\tilde{\epsilon}_{k}$ are equal, $n$ th-order stochastic dominance coincides with the Ekern's (1980) concept of increase in $n$ th-degree risk. As an example, $\tilde{\theta}_{k}$ is an increase in second degree risk over $\tilde{\epsilon}_{k}$ if $\tilde{\theta}_{k} \preceq_{S D_{2}} \tilde{\epsilon}_{k}$ and $E\left[\tilde{\theta}_{k}\right]=E\left[\tilde{\epsilon}_{k}\right]$. This is what Rothschild and Stiglitz (1970) defined as a "mean-preserving increase in risk". Similarly, Menezes et al. (1980) described an increase in third-degree risk, which is also called an "increase in downside risk" corresponding to $\tilde{\theta}_{k} \preceq_{S D_{3}} \tilde{\epsilon}_{k}$ with $E\left[\tilde{\theta}_{k}\right]=E\left[\tilde{\epsilon}_{k}\right]$ and $E\left[\tilde{\theta}_{k}^{2}\right]=E\left[\tilde{\epsilon}_{k}^{2}\right]$.

As before, we consider three scenarios: an increase in the first-period income risk, an increase in the second-period income risk and an increase in the child human capital risk.

\subsection{Income risk increase}

In the case where the household is confronted with a first-period income risk, the maximization problem is defined by Eq. (4). Let us now introduce another risk, $\tilde{\theta}_{1 w}$, that is riskier than $\tilde{\epsilon}_{1 w}$ in terms of $n$ th-order stochastic dominance $\left(\tilde{\theta}_{1 w} \preceq_{S D-n} \tilde{\epsilon}_{1 w}\right)$. The household's expected utility becomes

$$
W_{\tilde{\theta}_{1 w}}(m)=E\left[U\left(y_{1}+\tilde{\theta}_{1 w}, Z_{1}-m\right)\right]+\beta V\left(y_{2}+g(m), Z_{2}\right) .
$$


The optimal migration duration, $m_{\tilde{\theta}_{1 w}}^{*}$, is given by $W_{\tilde{\theta}_{1 w}}^{\prime}\left(m_{\tilde{\theta}_{1 w}}^{*}\right)=0$, that writes as

$$
-E\left[U^{(0,1)}\left(y_{1}+\tilde{\theta}_{1 w}, Z_{1}-m_{\tilde{\theta}_{1 w}}^{*}\right)\right]+\beta g^{\prime}\left(m_{\tilde{\theta}_{1 w}}^{*}\right) V^{(1,0)}\left(y_{2}+g\left(m_{\tilde{\theta}_{1 w}}^{*}\right), Z_{2}\right)=0 .
$$

Comparing the two optimal values, $m_{\tilde{\epsilon}_{1 w}}^{*}$ and $m_{\tilde{\theta}_{1 w}}^{*}$, we have (using Eq. (8)):

$$
W_{\tilde{\theta}_{1 w}}^{\prime}\left(m_{\tilde{\epsilon}_{1 w}}^{*}\right)=-E\left[U^{(0,1)}\left(y_{1}+\tilde{\theta}_{1 w}, Z_{1}-m_{\tilde{\epsilon}_{1 w}}^{*}\right)\right]+\beta g^{\prime}\left(m_{\tilde{\epsilon}_{1 w}}^{*}\right) V^{(1,0)}\left(y_{2}+g\left(m_{\tilde{\epsilon}_{1 w}}^{*}\right), Z_{2}\right) .
$$

Applying the properties of stochastic dominance, we can easily prove that this equation is negative (positive), i.e. $m_{\tilde{\theta}_{1 w}}^{*} \leq(\geq) m_{\tilde{\epsilon}_{1 w}}^{*}$, if $(-1)^{(1+s)} U^{(s, 1)} \leq(\geq) 0 \forall s=1, \ldots, n$.

If the income risk is introduced in the second period, the household's maximization problem is defined by Eq. (8). To look at how the household's behavior changes when the

second-period income risk increases, we replace $\tilde{\epsilon}_{2 w}$ by $\tilde{\theta}_{2 w}$ such that $\tilde{\theta}_{2 w} \preceq_{S D-n} \tilde{\epsilon}_{2 w}$. The household's expected utility becomes

$$
W_{\tilde{\theta}_{2 w}}(m)=U\left(y_{1}, Z_{1}-m\right)+\beta E\left[V\left(y_{2}+\tilde{\theta}_{2 w}+g(m), Z_{2}\right)\right] .
$$

The optimal migration duration, $m_{\tilde{\theta}_{2 w}}^{*}$, is given by $W_{\tilde{\theta}_{2 w}}^{\prime}\left(m_{\tilde{\theta}_{2 w}}^{*}\right)=0$, that writes as

$$
-U^{(0,1)}\left(y_{1}, Z_{1}-m_{\tilde{\theta}_{2 w}}^{*}\right)+\beta g^{\prime}\left(m_{\tilde{\theta}_{2 w}}^{*}\right) E\left[V^{(1,0)}\left(y_{2}+\tilde{\theta}_{2 w}+g\left(m_{\tilde{\theta}_{2 w}}^{*}\right), Z_{2}\right)\right]=0 .
$$

Evaluating $W_{\tilde{\theta}_{2 w}}^{\prime}$ at $m_{\tilde{\epsilon}_{2 w}}^{*}$, we have

$$
W_{\tilde{\theta}_{2 w}}^{\prime}\left(m_{\tilde{\epsilon}_{2 w}}^{*}\right)=-U^{(0,1)}\left(y_{1}, Z_{1}-m_{\tilde{\epsilon}_{2 w}}^{*}\right)+\beta g^{\prime}\left(m_{\tilde{\epsilon}_{2 w}}^{*}\right) E\left[V^{(1,0)}\left(y_{2}+\tilde{\theta}_{2 w}+g\left(m_{\tilde{\epsilon}_{2 w}}^{*}\right), Z_{2}\right)\right] .
$$

Following a similar reasoning as previously, this condition is negative (positive), i.e. $m_{\tilde{\theta}_{2 w}}^{*} \leq$ $(\geq) m_{\tilde{\epsilon}_{2 w}}^{*}$, if $(-1)^{(1+s)} V^{(s+1,0)} \geq(\leq) 0 \forall s=1, \ldots, n$. We obtain the following result:

\section{Proposition 4}

An increase in the first-period income risk in terms of nth-order stochastic dominance decreases (increases) the optimal migration duration, $m_{\tilde{\theta}_{1 w}}^{*} \leq(\geq) m_{\tilde{\epsilon}_{1 w}}^{*}$, for all households such that $(-1)^{(1+k)} U^{(k, 1)} \leq(\geq) 0 \forall k=1, \ldots, n$.

An increase in the second-period income risk in terms of nth-order stochastic dominance 
increases (reduces) the optimal migration duration, $m_{\tilde{\theta}_{2 w}}^{*} \geq(\leq) m_{\tilde{\epsilon}_{2 w}}^{*}$, for all households such that $(-1)^{(1+k)} V^{(k+1,0)} \leq(\geq) 0 \forall k=1, \ldots, n$.

If we restrict changes in the income risk to the special case of increases in risk as defined by Ekern (1980), then a nth-degree increase in the first (second)-period income risk decreases (increases) the optimal migration duration, for all households such that $(-1)^{(1+n)} U^{(n, 1)} \leq 0$ $\left((-1)^{(1+n)} V^{(n+1,0)} \leq 0\right)$. Note that Proposition 2 corresponds to the special case of Ekern's second-order increase in risk since random variables $\tilde{\epsilon}_{1 w}$ and $\tilde{\epsilon}_{2 w}$ introduced in section 3 are assumed actuarially neutral $\left(E\left[\tilde{\epsilon}_{1 w}\right]=E\left[\tilde{\epsilon}_{2 w}\right]=0\right)$.

As an illustration, we can also consider the particular case of a third-degree Ekern's increase in risk where $\tilde{\epsilon}_{2 w}=\left[-k, \tilde{l} ; \frac{1}{2}, \frac{1}{2}\right]$ and $\tilde{\theta}_{2 w}=\left[0,-k+\tilde{l} ; \frac{1}{2}, \frac{1}{2}\right]$ with $k>0$ and $\tilde{l}$ a zero-mean random variable $E[\tilde{l}]=0$ i.e. a case where both lotteries have the same expected mean and the same variance. We have, therefore, $m_{\tilde{\theta}_{2 w}}^{*} \geq m_{\tilde{\epsilon}_{2 w}}^{*}$ if the household is temperate in the second period wealth level (i.e. if $V^{(4,0)} \leq 0$ ).

\subsection{Child human capital risk increase}

When the household is faced with a child human capital risk in the second period, her maximization problem is defined by Eq. (12). Let's replace $\tilde{\epsilon}_{2 z}$ by another child human capital risk, $\tilde{\theta}_{2 z}$, riskier than $\tilde{\epsilon}_{2 z}$ in terms of $n$ th-order stochastic dominance. The household's problem becomes

$$
W_{\tilde{\theta}_{2 z}}(m)=U\left(y_{1}, Z_{1}-m\right)+\beta E\left[V\left(y_{2}+g(m), Z_{2}+\tilde{\theta}_{2 z}\right)\right] .
$$

Let's denote $m_{\tilde{\theta}_{2 z}}^{*}$ the optimal migration duration. Evaluating the FOC of $W_{\tilde{\theta}_{2 z}}$ at $m_{\tilde{\epsilon}_{2 z}}^{*}$, we get

$$
W_{\tilde{\theta}_{2 z}}^{\prime}\left(m_{\tilde{\epsilon}_{2 z}}^{*}\right)=-U^{(0,1)}\left(y_{1}, Z_{1}-m_{\tilde{\epsilon}_{2 z}}^{*}\right)+\beta g^{\prime}\left(m_{\tilde{\epsilon}_{2 z}}^{*}\right) E\left[V^{(1,0)}\left(y_{2}+g\left(m_{\tilde{\epsilon}_{2 z}}^{*}\right), Z_{2}+\tilde{\theta}_{2 z}\right)\right] .
$$

This condition is negative (positive), i.e. $m_{\tilde{\theta}_{2 z}}^{*} \leq(\geq) m_{\tilde{\epsilon}_{2 z}}^{*}$ if $(-1)^{(1+s)} V^{(1, s)} \geq(\leq) 0 \forall s=$ $1, \ldots, n$. We obtain the following result: 


\section{Proposition 5}

An increase in the second-period child human capital risk in terms of nth-order stochastic dominance increases (reduces) the optimal migration duration, $m_{\tilde{\theta}_{2 z}}^{*} \geq(\leq) m_{\tilde{\epsilon}_{2 z}}^{*}$, for all households such that $(-1)^{(1+k)} V^{(1, k)} \leq(\geq) 0 \forall k=1, \ldots, n$.

Similarly, if we restrict changes in the child human capital risk to the special case of increases in risk as defined by Ekern (1980), a $n$ th-degree increase in the second-period child human capital risk increases the optimal migration duration, for all households such that $(-1)^{(1+n)} V^{(1, n)} \leq 0$. Note that Proposition 3 corresponds to the particular case of this last result where $n=2$.

\section{Risky return on the migration duration}

In Section 3, we investigated the effects of the introduction of a risk on the first period wealth endowment, a risk on the second period wealth endowment, and a risk on the second period child human capital endowment. However, uncertainty can also affect the efficiency of the migration duration, $g(m)$. Migrant workers engaged in the informal sector typically suffer high levels of job insecurity (as discussed in Section 3). In China, for example, one important source of insecurity for migrant workers is the delayed payments and non-payment problems (Chan, 2005; Price, 2011). This makes the earnings that the migrant parent may bring back home in the second period risky, which we denote by $\tilde{g}(m)$.

The riskiness can appear in two different forms. It can be considered as a fixed amount (i.e independent of the migration duration), and, thus, modeled by an additive form: $\tilde{g}(m)=$ $g(m)+\tilde{\eta}$, where $\tilde{\eta}$ is a zero-mean random variable. It can also be considered as proportional to the migration duration, it is modeled, in this case, with a multiplicative form: $\tilde{g}(m)=g(m) \tilde{\eta}$. It is assumed that realisations of the random variable $\tilde{\eta}$ are all strictly positive to ensure that the migration duration is always effective. In the case where the realisation of $\tilde{\eta}$ is $\eta$, such that $0<\eta<1(\eta=1, \eta>1)$, the effectiveness of the migration duration is lower (equal to, bigger) than the one under risk. We assume that $E(\tilde{\eta})=1$.

In the first case where the riskiness appears in an additive form, the household's expected 
utility writes as

$$
U\left(y_{1}, Z_{1}-m\right)+\beta E\left[V\left(y_{2}+g(m)+\tilde{\eta}, Z_{2}\right)\right]
$$

Technically, this case is identical to the case of the introduction of a second-period income risk, analysed in the previous section. Results are given by Proposition 4.

In the second case where the riskiness appears in a multiplicative form, the difference is important because the presence of risk makes the marginal productivity of the migration duration random. For the sake of simplicity, we consider $y_{2}=0$. The household's expected utility writes therefore as

$$
W_{\tilde{\eta}}(m)=U\left(y_{1}, Z_{1}-m\right)+\beta E\left[V\left(g(m) \tilde{\eta}, Z_{2}\right)\right]
$$

We denote as $m_{\tilde{\eta}}^{*}$ the solution of this problem. It verifies $W_{\tilde{\eta}}^{\prime}\left(m_{\tilde{\eta}}^{*}\right)=0$ which writes as

$$
-U^{(0,1)}\left(y_{1}, Z_{1}-m_{\tilde{\eta}}^{*}\right)+\beta E\left[g^{\prime}\left(m_{\tilde{\eta}}^{*}\right) \tilde{\eta} V^{(1,0)}\left(g\left(m_{\tilde{\eta}}^{*}\right) \tilde{\eta}, Z_{2}\right)\right]=0
$$

Let us now replace $\tilde{\eta}$ with another risk $\tilde{\zeta}$ which is riskier than $\tilde{\eta}$ in terms of $n$ th-order stochastic dominance, the household's problem is, therefore, the following:

$$
W_{\tilde{\zeta}}(m)=U\left(y_{1}, Z_{1}-m\right)+\beta E\left[V\left(g(m) \tilde{\zeta}, Z_{2}\right)\right]
$$

The optimal level of decrease in the child human capital $m_{\tilde{\zeta}}^{*}$ is given by

$$
-U^{(0,1)}\left(y_{1}, Z_{1}-m_{\tilde{\zeta}}^{*}\right)+\beta E\left[g^{\prime}\left(m_{\tilde{\zeta}}^{*}\right) \tilde{\zeta} V^{(1,0)}\left(g\left(m_{\tilde{\zeta}}^{*}\right) \tilde{\zeta}, Z_{2}\right)\right]=0
$$

Evaluating $W_{\tilde{\zeta}}^{\prime}$ at $m_{\tilde{\eta}}^{*}$, we have

$$
W^{\prime} \tilde{\zeta}\left(m_{\tilde{\eta}}^{*}\right)=\beta E\left[g^{\prime}\left(m_{\tilde{\eta}}^{*}\right) \tilde{\zeta} V^{(1,0)}\left(g\left(m_{\tilde{\eta}}^{*}\right) \tilde{\zeta}, Z_{2}\right)\right]-\beta E\left[g^{\prime}\left(m_{\tilde{\eta}}^{*}\right) \tilde{\eta} V^{(1,0)}\left(g\left(m_{\tilde{\eta}}^{*}\right) \tilde{\eta}, Z_{2}\right)\right]
$$

We introduce the following function $G: G(\eta)=\eta V^{(1,0)}\left(g\left(m_{\tilde{\eta}}^{*}\right) \eta, Z_{2}\right) \forall \eta$. Using this notation, the previous equation equivalently rewrites as

$$
W_{\tilde{\zeta}}^{\prime}\left(m_{\tilde{\eta}}^{*}\right)=\beta g^{\prime}\left(m_{\tilde{\eta}}^{*}\right)(E[G(\tilde{\zeta})]-E[G(\tilde{\eta})])
$$


Applying the properties of stochastic dominance, Eq. (28) is negative (positive), resulting in $m_{\tilde{\zeta}}^{*} \leq(\geq) m_{\tilde{\eta}}^{*}$, if $(-1)^{(1+k)} G^{(k)} \geq(\leq) 0 \forall k=1, \ldots, n$, i.e. if $-y \frac{V^{(k+1,0)}(y, Z)}{V^{(k, 0)}(y, Z)} \leq(\geq) k$ $\forall k=1, \ldots, n$. We summarize this result in the following proposition:

\section{Proposition 6}

Given two risky returns, $g(m) \tilde{\zeta}$ and $g(m) \tilde{\eta}$, with $\tilde{\zeta}$ riskier than $\tilde{\eta}$ via $n$-th order stochastic dominance $\left(\tilde{\zeta} \preceq_{S D-n} \tilde{\eta}\right)$, the optimal migration duration, $m_{\tilde{\zeta}}^{*}$, is longer (shorter) than the optimal migration duration $m_{\tilde{\eta}}^{*}\left(m_{\tilde{\zeta}}^{*} \geq(\leq) m_{\tilde{\eta}}^{*}\right)$, for all households such that $-y \frac{V^{(k+1,0)}(y, Z)}{V^{(k, 0)}(y, Z)} \geq$ $(\leq) k \forall(y, Z), \forall k=1, \ldots, n$.

Proposition 6 shows that the increase or the decrease in the optimal migration duration is governed by the value of the $n$-th relative risk aversion ${ }^{15}$.

Let's, in a further step, illustrate Proposition 6 in the case of the particular case of Ekern's dominance of order $2\left(\tilde{\zeta} \preceq_{\text {Ekern-2 }} \tilde{\eta}\right): \tilde{\zeta}$ is a zero-mean risk and $\tilde{\eta}$ is the degenerated random variable that equals to 0 . We analyze here how the introduction of a risky return $\tilde{\zeta}$ modifies the optimal migration duration in comparison with the situation without risk. Hence the following proposition:

\section{Proposition 7}

The introduction of a risky return on the migration duration increases (decreases) the optimal migration duration $\left(m_{\tilde{\eta}}^{*} \geq(\leq) m^{*}\right)$, if the household has a relative prudence greater (smaller) than 2.

The household's behavior in Proposition 7 is the result of the interaction of two effects. On the one hand, a longer migration duration increases the expected household income in the future. According to the preference for the disaggregation of harms, a prudent household would like this increase in income as she prefers to have a higher wealth in the period where she faces a risk. On the other hand, an additional time unit in the migration duration is similar to investing in a risky asset since the return on this migration duration is risky. However the household is supposed to be risk averse, she does not like this second effect.

\footnotetext{
${ }^{15}$ Note that if the second-period income was not zero, the results would involve a "partial $n$-th degree risk aversion measure" instead of a "relative $n$-th degree risk aversion measure" (see e.g., Chiu et al., 2012).
} 
Therefore, the household is faced with two conflicting incentives when the return on the migration duration is risky. Prudence motivates them to increase the migration duration, while risk aversion pushes them to decrease it. As a result, the household opts for an increase in the migration duration if the feeling of prudence "exceeds" the feeling of risk aversion, that is whenever her relative prudence is greater than 2 .

This result means that if the household has a relative prudence that is greater than 2 , a left-behind child is better off when the household bears no risk than if she is faced with a risky return on the migration duration, and that if the household is faced with a risky return, the left-behind child is better off if the household has a relative prudence that is lower than 2 , i.e. if risk aversion is "stronger" for the household than prudence.

\section{Conclusion}

This paper investigates how household's higher order risk aversion attitudes affect the optimal migration duration depending on the risk levels considered. To do so, we use a two-period framework where the household's welfare depends on both the household income and the child human capital status, and we consider four configurations of risks: first-period income risk, second-period income risk, second-period child human capital risk and a risky return on the migration duration.

The model generates a number of interesting insights. First, the detailed comparative statics analysis shows that, in the absence of risk, the optimal migration duration reacts to changes in both the household income and the child human capital status. However, we find that the sign of the child human capital state dependence dominates the direction of the effects on the migration duration, when we consider increases in the household income during the migration of the parent and increases in the future child human capital level when the migrant parent would have been back.

In a second step, we introduce separately the different risks in the decision-making process of the household. We confirm Dustmann (1997)'s finding that prudence plays a fundamental role when comparing risk levels à la Rotschild-Stiglitz, and we show that risk aversion attitudes of order higher than two also affect the direction of changes in the optimal migration duration with respect to changes in levels of a given risk. Finally, we show that, for a given 
level of risk, the nature of the risk aversion attitude of this level varies depending on the configuration (type and timing) of the risk considered.

Future research could draw on this analysis in at least two ways. First, theoretically, going beyond the separate analysis of each risk as we did here would help understand how results change when income and child human capital risks are considered simultaneously, either or not as independent risks. Second, empirically, assuming that households are typically risk averse, one testable implication of our model is that higher order risk attitudes determine the effect on the migration duration caused by changes in the future household income risk properties to which the household is exposed (Proposition 4). The household income process over time can be used to identify higher order risks. Second-order risk changes can be measured with estimations of the variance of the residuals in the household income regression, while the estimated skewness and kurtosis are the third- and the forth-order changes in risk, respectively. In a world where households could perceive whether they face a risk or not, and would not self-select into environments with different risks, if the future household income in the second period (when the migrant parent returns home) were to become risky and induce an increase in the migration duration with respect to a situation without risk, this would suggest the importance of the household behavior predicted by its prudence in wealth. Increases in the migration duration following increased skewness and kurtosis can be used as evidence for temperance and edginess, respectively. Another important empirical implication of our work is the investigation of the sign of the interaction between child human capital and wealth in household utility functions (i.e., the child human capital state dependence). Ever since Grossman (1972) developed his model of demand-for-health, many empirical studies in health economics have tried to determine the sign of the health state dependence, i.e. how the marginal utility of income changes with the health status (Viscusi and Evans, 1990; Finkelstein et al., 2013; Kools and Knoef, 2019). Our work shows that, in the study of migration problems, the interaction between child human capital and wealth is also crucial. No study, to our knowledge, has ever empirically investigated the sign and the magnitude of this relationship.

\section{Declarations}


Funding Not applicable.

Conflicts of interest The authors declare that they have no conflict of interest.

Availability of data and material Not applicable.

Code availability Not applicable.

\section{Acknowledgements}

I would like to thank Béatrice Rey and Sylvie Démurger for their helpful comments.

\section{Appendix}

\section{Proof of proposition 1}

In order to determine the comparative statics properties of the optimal level of child human capital disinvestment, $m^{*}$, we use the implicit function theorem. The FOC writes as $F\left(y_{1}, y_{2}, Z_{1}, Z_{2}, m_{\tilde{\epsilon}_{1}, \tilde{\epsilon_{2}}}^{*}\right)=0$ where $m^{*}$ is a function of $y_{1}, y_{2}, Z_{1}$ and $Z_{2}$, then $m^{*}$ can be written as $m^{*}=m\left(y_{1}, y_{2}, Z_{1}, Z_{2}\right)$.

The FOC rewrites then as: $F\left(y_{1}, y_{2}, Z_{1}, Z_{2}, m\left(y_{1}, y_{2}, Z_{1}, Z_{2}\right)\right)=0$. It follows that $\frac{\partial F}{\partial k}+$ $\frac{\partial F}{\partial m} \frac{d m}{d k}=0, \forall k=y_{1}, y_{2}, Z_{1}, Z_{2} \Leftrightarrow \frac{d m}{d k}=-\frac{\frac{\partial F}{\partial k}}{\frac{\partial F}{\partial m}}, \forall k=y_{1}, y_{2}, Z_{1}, Z_{2}$.

Because the SOC is verified $\left(\frac{\partial F}{\partial m}<0\right)$, we get that $\operatorname{Sign}\left(\frac{d m}{d k}\right)=\operatorname{Sign}\left(\frac{\partial F}{\partial k}\right)$.

We obtain then the following.

$\frac{\partial F}{\partial y_{1}}=-U^{(1,1)}\left(y_{1}, Z_{1}-m^{*}\right)$. The sign of this expressin depends on the sign of $U^{(1,1)}$. If $U^{(1,1)}<0$ then $\frac{\partial F}{\partial y_{1}}>0$. If $U^{(1,1)}=0$ then $\frac{\partial F}{\partial y_{1}}=0$. If $U^{(1,1)}>0$ then $\frac{\partial F}{\partial y_{1}}<0$.

$\frac{\partial F}{\partial y_{2}}=\beta g^{\prime}\left(m^{*}\right) V^{(2,0)}\left(y_{2}+g\left(m^{*}\right), Z_{2}\right)<0, \frac{\partial F}{\partial Z_{1}}=-U^{(0,2)}\left(y_{1}, Z_{1}-m^{*}\right)>0$.

$\frac{\partial F}{\partial Z_{2}}=\beta g^{\prime}\left(m^{*}\right) V^{(1,1)}\left(y_{2}+g\left(m^{*}\right), Z_{2}\right)$. The sign of this expression depends on the sign of the second cross-derivative $V^{(1,1)}$ (since $g^{\prime}\left(m^{*}\right)>0$ according to our assumptions). If $V^{(1,1)}<0$ then $\frac{\partial F}{\partial Z_{2}}<0$. If $V^{(1,1)}=0$ then $\frac{\partial F}{\partial Z_{2}}=0$. If $V^{(1,1)}>0$ then $\frac{\partial F}{\partial Z_{2}}>0$.

This ends the proof. 


\section{References}

Antman, F. M. (2011), 'The intergenerational effects of paternal migration on schooling and work: What can we learn from children's time allocations?', Journal of Development Economics 96(2), 200-208.

Antman, F. M. (2013), The impact of migration on family left behind, in 'International handbook on the economics of migration', Edward Elgar Publishing.

Baiardi, D. and Menegatti, M. (2011), 'Pigouvian tax, abatement policies and uncertainty on the environment', Journal of Economics 103(3), 221-251.

Bazzi, S. (2017), 'Wealth heterogeneity and the income elasticity of migration', American Economic Journal: Applied Economics 9(2), 219-55.

Becker, G. S., Kominers, S. D., Murphy, K. M. and Spenkuch, J. L. (2018), 'A theory of intergenerational mobility', Journal of Political Economy 126(S1), S7-S25.

Behrman, J. R. (1997), 'Intrahousehold distribution and the family', Handbook of Population and Family Economics 1, 125-187.

Chan, A. (2005), 'Recent trends in Chinese labour issues - signs of change', China Perspectives 2005(57).

Chiu, W. H., Eeckhoudt, L. and Rey, B. (2012), 'On relative and partial risk attitudes: theory and implications', Economic Theory 50(1), 151-167.

Cortes, P. (2015), 'The feminization of international migration and its effects on the children left behind: Evidence from the philippines', World Development 65, 62-78.

Courbage, C. and Rey, B. (2016), 'Decision thresholds and changes in risk for preventive treatment', Health economics 25(1), 111-124.

Currie, J. (2020), 'Child health as human capital', Health Economics 29(4), 452-463.

Currie, J., Zivin, J. G., Mullins, J. and Neidell, M. (2014), 'What do we know about short-and long-term effects of early-life exposure to pollution?', Annu. Rev. Resour. Econ. 6(1), 217247.

De La Rupelle, M., Deng, Q., Shi, L. and Vendryes, T. (2009), 'Land rights insecurity and temporary migration in rural China'.

Dustmann, C. (1997), 'Return migration, uncertainty and precautionary savings', Journal of Development Economics 52(2), 295-316.

Dustmann, C. (2003), 'Return migration, wage differentials, and the optimal migration duration', European Economic Review 47(2), 353-369.

Eeckhoudt, L., Rey, B. and Schlesinger, H. (2007), 'A good sign for multivariate risk taking', Management Science 53(1), 117-124.

Eeckhoudt, L. and Schlesinger, H. (2006), 'Putting risk in its proper place', American Economic Review 96(1), 280-289.

Eeckhoudt, L. and Schlesinger, H. (2008), 'Changes in risk and the demand for saving', Journal of Monetary Economics 55(7), 1329-1336.

Eeckhoudt, L. and Schlesinger, H. (2013), Higher-order risk attitudes, in 'Handbook of Insurance', Springer, pp. 41-57. 
Ekern, S. (1980), 'Increasing nth degree risk', Economics Letters 6(4), 329-333.

Fellmeth, G., Rose-Clarke, K., Zhao, C., Busert, L. K., Zheng, Y., Massazza, A., Sonmez, H., Eder, B., Blewitt, A., Lertgrai, W. et al. (2018), 'Health impacts of parental migration on left-behind children and adolescents: a systematic review and meta-analysis', The Lancet 392(10164), 2567-2582.

Finkelstein, A., Luttmer, E. F. and Notowidigdo, M. J. (2013), 'What good is wealth without health? the effect of health on the marginal utility of consumption', Journal of the European Economic Association 11(suppl_1), 221-258.

Galor, O. and Stark, O. (1991), 'The probability of return migration, migrants' work effort, and migrants' performance', Journal of development economics 35(2), 399-405.

Giles, J. and Yoo, K. (2007), 'Precautionary behavior, migrant networks, and household consumption decisions: An empirical analysis using household panel data from rural china', The Review of Economics and Statistics 89(3), 534-551.

Grossman, M. (1972), 'On the concept of health capital and the demand for health', Journal of Political economy 80(2), 223-255.

Harris, J. R. and Todaro, M. P. (1970), 'Migration, unemployment and development: a two-sector analysis', American Economic Review 60(1), 126-142.

Heckman, J. J. and Mosso, S. (2014), 'The economics of human development and social mobility', Annu. Rev. Econ. 6(1), 689-733.

Ingersoll, J. E. (1987), Theory of financial decision making, Vol. 3, Rowman \& Littlefield.

International Labour Office (2018), 'Women and men in the informal economy: A statistical picture (third edition)'. https://www.ilo.org/wcmsp5/groups/public/---dgreports/ ---dcomm/documents/publication/wcms_626831.pdf.

IOM (2020), World Migration Report 2020, International Organization for Migration, Geneva. Available at https://publications.iom.int/books/world-migration-report-2020.

Kasy, M. et al. (2012), Intergenerational mobility and optimal income taxation, Technical report.

Katz, E. and Stark, O. (1986), 'Labor migration and risk aversion in less developed countries', Journal of labor Economics 4(1), 134-149.

Kimball, M. S. (1992), 'kprecautionary motives for holding assets. $\mathrm{v}$ in the new palgrave dictionary of money and finance. p. newman, m. milgate, and j. falwell, eds'.

Kimball, M. S. et al. (1990), 'Precautionary saving in the small and in the large', Econometrica 58(1), 53-73.

Kools, L. and Knoef, M. (2019), 'Health and consumption preferences; estimating the health state dependence of utility using equivalence scales', European Economic Review 113, 4662.

Lajeri-Chaherli, F. (2004), 'Proper prudence, standard prudence and precautionary vulnerability', Economics Letters 82(1), 29-34.

Liu, D. and Menegatti, M. (2019a), 'Optimal saving and health prevention', Journal of Economics 128(2), 177-191. 
Liu, D. and Menegatti, M. (2019b), 'Precautionary investment in wealth and health', Journal of Risk and Insurance 86(1), 237-255.

Loury, G. C. (1981), 'Intergenerational transfers and the distribution of earnings', Econometrica pp. 843-867.

Mazzucato, V., Cebotari, V., Veale, A., White, A., Grassi, M. and Vivet, J. (2015), 'International parental migration and the psychological well-being of children in ghana, nigeria, and angola', Social Science \& Medicine 132, 215-224.

McKenzie, D. and Rapoport, H. (2006), Can migration reduce educational attainment? Evidence from Mexico, The World Bank.

Myerson, R. (2017), 'Policy analysis with endogenous migration decisions: The case of leftbehind children in China', Available at https://ssrn.com/abstract=3058134 .

Nguyen, C. V. (2016), 'Does parental migration really benefit left-behind children? comparative evidence from ethiopia, india, peru and vietnam', Social Science \& Medicine 153, 230-239.

OECD (2019), International Migration Outlook 2019, OECD, Paris. Available at https://www.oecd-ilibrary.org/content/publication/c3e35eec-en.

Paxson, C. H. (1992), 'Using weather variability to estimate the response of savings to transitory income in thailand', The American Economic Review pp. 15-33.

Pinto-Jayawardena, K. et al. (2006), Left behind, left out: The impact on children and families of mothers migrating for work abroad: Summary report, Technical report, Save the Children in Sri Lanka, Colombo.

Price, R. (2011), 'What would confucius say about arrears in wages?', Available at SSRN 1764344 .

Rose, E. (2001), 'Ex ante and ex post labor supply response to risk in a low-income area', Journal of Development Economics 64(2), 371-388.

Rothschild, M. and Stiglitz, J. E. (1970), 'Increasing risk: I. a definition', Journal of Economic theory 2(3), 225-243.

Stark, O. (1991), 'The migration of labor'.

Stark, O. and Bloom, D. E. (1985), 'The new economics of labor migration', The American Economic Review 75(2), 173-178.

Stark, O. and Levhari, D. (1982), 'On migration and risk in ldcs', Economic development and cultural change $\mathbf{3 1}(1)$, 191-196.

Trautmann, S. T. and van de Kuilen, G. (2018), 'Higher order risk attitudes: A review of experimental evidence', European Economic Review 103, 108-124.

Treich, N. (2010), 'Risk-aversion and prudence in rent-seeking games', Public Choice 145(34), 339-349.

Viscusi, W. K. and Evans, W. N. (1990), 'Utility functions that depend on health status: estimates and economic implications', The American Economic Review pp. 353-374.

World Health Organization (2018), Air Pollution and Child Health: Prescribing Clean Air, World Health Organization. 